\title{
SIADH in COVID 19 infection, an association or cause : A case report
}

\author{
Karishma Shamarukh*1, Sharmin Rahman², Umme Kulsum Chy ${ }^{3}$, Amina Sultana ${ }^{4}$, Mohammad Omar Faruq ${ }^{5}$
}

\begin{abstract}
:
One of the leading cause of hyponatremia is syndrome of inappropriate antidiuretic hormone secretion (SIADH). Various etiologies of hyponatraemia have been observed till today but its association with Covid leading to SIADH is rare. Therefore, we present a case where SIADH was associated with Covid-19 pneumonia. This was a case of a 66 years old male with multiple co-morbidities presenting with symptoms of Covid infection including generalized weakness. After confirming Covid 19 infection management was started accordingly but patient's weakness seemed to increase. He was found to have low sodium level of $105 \mathrm{mmol} / \mathrm{L}$ and investigations confirmed that he was having SIADH. He was treated with hypertonic saline, fluid restriction and his symptoms and laboratory parameters gradually improved.
\end{abstract}

Key words: Hyponatraemia, SARS Cov-2, plasma osmolality, SIADH, urinary sodium.

\section{Introduction:}

Hyponatraemia in adults, generally is defined as a serum sodium less than $135 \mathrm{mmol} / \mathrm{L}$ and is the most common electrolyte abnormality observed in hospital inpatients ${ }^{1}$.

It is estimated that mild hyponatraemia (serum sodium $125-135 \mathrm{mmol} / \mathrm{L})$ is observed in $15-30 \%$ of patients in hospitals ${ }^{2}$. Often times, due to the increased release of a hydrous hormone called antidiuretic (ADH), the sodium in the blood becomes diluted resulting in hyponatremia.

Hyponatremia is the most prevalent hydro electrolytic disorder in clinical practice. Coexistence of hyponatremia and Covid-19 infection has been reported in recent studies, but the possible underlying pathophysiological mechanism has yet to be explained clearly ${ }^{3,4}$.

SIADH is an important cause of hyponatraemia. In addition to a complete medical history and physical examination, to confirm diagnosis of SIADH, blood and urine tests need to be performed to measure sodium, potassium, and osmolality (concentration of solution in the blood and urine). The diagnosis requires concentrated urine (Sodium $>20 \mathrm{mmol} / \mathrm{L}$ and osmolality $>100 \mathrm{mOsm} / \mathrm{kg}$ ) in the presence of hyponatraemia (serum sodium $<125 \mathrm{mmol} / \mathrm{L}$ ) and low plasma osmolality $(<260 \mathrm{mOsm} / \mathrm{kg})$, in the absence of hypovolemia, edema or diuretics. Malignancy, CNS disorders, pneumonia,

1. Intensivist, Covid ICU, United Hospital Ltd.

2. Specialist, Internal Medicine United hospital Ltd.

3. Junior Consultant General ICU United Hospital Ltd.

4. Associate Consultant In charge Covid ICU, United Hospital Ltd.

5. Chief Consultant General ICU \& Emergency, United Hospital Ltd.

*Corresponding Author:

Dr. Karishma Shamarukh, MBBS, MRCP (UK)

Intensivist, Covid Intensive Care Unit

United Hospital Limited, Dhaka 1212, Bangladesh.

E-mail : shamarukhk@gmail.com

Cell: $\quad+8801830072114$ endocrine abnormalities, various drugs are identified as cause of SIADH.

Coronavirus 2 (SARS-CoV-2) causes corona virus disease 2019 (COVID-19). Route of transmission is via droplet and direct contact. SARS-CoV-2 is an enveloped RNA virus. The clinical presentation varies from a mild influenza like illness to potentially fatal acute respiratory distress syndrome. There is an association of low serum sodium and covid-19 in this study. An incorrect diagnosis of the underlying cause of hyponatraemia can lead to inadequate treatment, resulting in increased morbidity, ICU admission, and increased length of stay in hospital.

Osmolality is a fundamental measurement of the total solute concentration of body fluids, including but not limited to, whole blood, serum,plasma, urine and stool $^{5}$. Serum and urine osmolality are integral to the diagnosis and management of hyponatremia. The use of urine osmolality to establish a correct underlying diagnosis of hyponatremia is critical to avoid inappropriate treatment and potential harm to the patient $t^{6,7}$.

Understanding the underlying causes of hyponatremia is important because the treatment options vary widely from fluid resuscitation for hyponatremia driven by volume depletion to volume restriction for hyponatremia driven by SIADH. Understanding this etiology is of even greater importance with Covid-19 patients because they require cautious and conservative fluid resuscitation to avoid exacerbating underlying respiratory distress and pulmonary inflammation ${ }^{8,9}$.

\section{Case Report:}

A 66years old male with the past medical history of Diabetes Mellitus, Hypertension, Ischemic Heart Disease and Hypothyroidism presented with fever, anosmia and generalized weakness. His signs symptoms correlated with Covid 19 and there was widespread transmission of Covid 19 in the community as well. Thus, during his first visit nasopharyngeal swab was taken for SARS-CoV-2 PCR which came back positive. Conservative home management for Covid 19 was given at that time. 
Three days later patient presented to our facility with severe restlessness and respiratory distress. There was no associated history of vomiting, increase oral intake of fluid, introduction of any new drugs or change of his urinary habit. He was agitated, afebrile, pulse was 68 beats per min, BP-140/80mm-Hg, respiratory rate was 30 breaths per minute, an oxygen saturation $\left(\mathrm{SpO}_{2}\right)$ was $99 \%$ with 10 liter oxygen via face mask. Apart from agitation there was no focal neurological deficit. Other general and systemic examinations were normal.

Laboratory findings revealed serum sodium $105 \mathrm{mmol} / \mathrm{L}$ (136-145mmol/L), serum creatinine was $1.07 \mathrm{mg} / \mathrm{dl}$ $(0.72-1.25 \mathrm{mg} / \mathrm{dl})$, blood urea $40 \mathrm{mg} / \mathrm{dl}(17-43 \mathrm{mg} / \mathrm{dl})$, a rise in white cell count $16.910^{\wedge} 3 / \mu 1$ (normal range 4-11) with neutrophilic leukocytosis of $89.9 \%$ (40-75) and lymphopenia of $4.6 \%(20-50)$,thyroid stimulating hormone was found to be normal. Chest X-ray revealed patchy infiltrations on both lungs (Fig:A). ECG showed no significant abnormality. CT scan of head was unremarkable. Few more workup was done results showed urinary sodium $38.0 \mathrm{mEq} / \mathrm{L}$, serum osmolality of $200 \mathrm{mOsm} / \mathrm{kg}$ and urine osmolality of $287.0 \mathrm{mOsm} / \mathrm{kg}$.As all other workup for hyponatraemia was non-significant, he was diagnosed as SIADH due to Covid Pneumonia.

The treatment was started with slow hypertonic saline 3\% infusion, injectable broad spectrum antibiotics, IV Remdisivir $200 \mathrm{mg}$ stat then $100 \mathrm{mg}$ once daily for 5 days, LMWH $60 \mathrm{mg}$ Subcutaneously twice daily, Inj. dexamethasone 6mg I/V 12 hourly initially which was gradually tapered later and high flow oxygen. Oral fluid was restricted to 1litre per day. Serum sodium was corrected slowly and was observed over next 3 days which reached $129 \mathrm{mmol} / 1$. His neurological symptoms improved dramatically. Later on he was placed on oral $\mathrm{NaCl}$ tablet. His oxygen demand reduced and was maintained on room air.

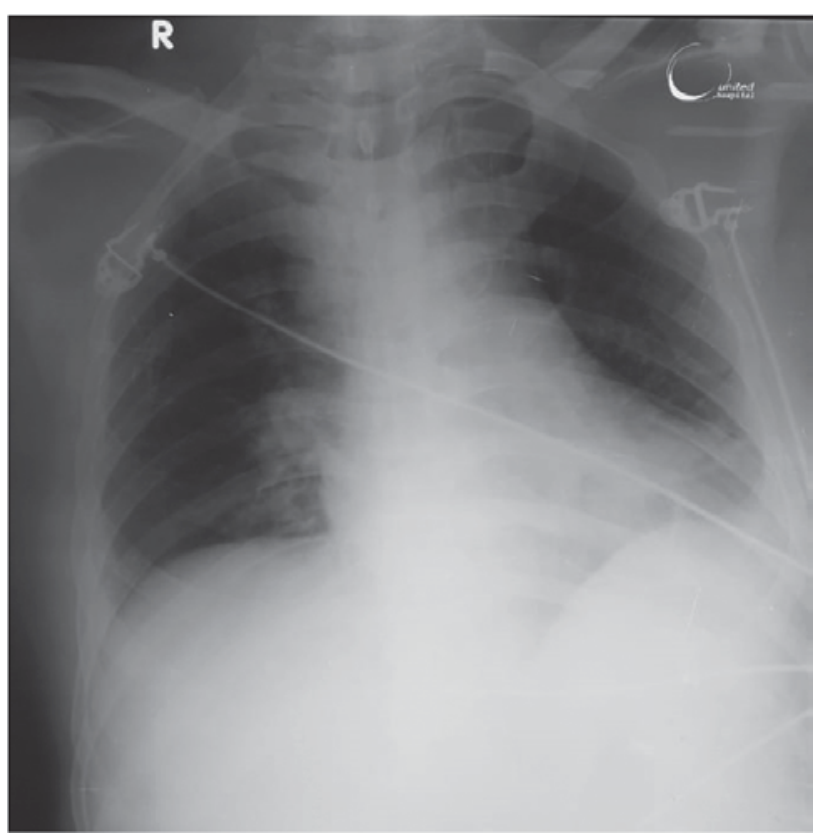

Fig A

\section{Discussion:}

Patients with Hyponatraemia usually present with nausea, malaise, confusion, lethargy, headache, convulsion and coma (in severe cases). Whereas, patients with stroke presents commonly with weakness and signs of focal neurological deficit.

In our patient, acute confusional state on the background of Covid-19 pneumonia and having severe respiratory distress was indicative of a complication of Covid-19, though there were no signs of focal neurological deficit at the time presentation. Still, keeping stroke in our mind necessary investigations and CT-scan of brain was done to exclude stroke.

There has been few case reports on Covid-19 pneumonia associated SIADH worldwide. In one of the case studies ${ }^{10}$ a middle aged male, 58 years, was diagnosed with SIADH who improved with fluid restriction alone. In this study three cases were discussed among which one had presentation with abdominal pain as the main complaint rest had similar constitutional symptoms. Another case study ${ }^{11}$ also discussed about 80 years old woman who had some malaise and dyspnea and a 62 years old man with cough and fever. Both of these patients were Covid-19 positive and later were confirmed to have SIADH. A 37 year old male having a similar presentation was described in another case study ${ }^{12}$, he was confirmed to have SIADH. With conservative management this patient was also improved dramatically. Though all these studies could not explain the exact reason behind presentation of SIADH with SARS Cov-2 virus, SIADH was suggested to be the cause of hyponatremia and management was done accordingly. According to literature there has been association of community acquired pneumonia with SIADH, which is around $50 \%{ }^{13}$.

The mechanism of SIADH in pneumonia is not well established; however, the role of low intravascular fluid volume and low extracellular fluid osmolality has been established in animal model studies ${ }^{14,15}$.

In cases of intravascular volume depletion, carotid body, baro receptors and aorta activate the renin-angiotensin system. Which later triggers a baroreceptor-mediated, nonosmotic $\mathrm{ADH}$ secretion $^{16,17}$. In the case of decreased intravascular osmolality, osmoreceptors activate and increase the ADH secretion $^{18}$.

It is hypothesized that Covid -19 not only affects our physical wellbeing but also hampers our emotional status and routine day-to-day activities. Social stigma in few areas has itself made the patients emotionally labile and stressed. These kinds of emotional, physical, or psychological stresses and pain associated with infections stimulate the hypothalamohypophyseal axis, leading to $\mathrm{ADH}$ release. Also, stress activates the cortical neurons, which stimulate the hypothalamus to secrete $\mathrm{ADH}^{19}$.

The critically ill patients suffer injury to lung parenchyma which later leads to hypoxic pulmonary vasoconstriction as a consequence of ventilation-perfusion mismatch. Ultimately 
this leads to an inadequate filling of the left atrium. Consequent on this, a decreased left atrial stretch and increased $\mathrm{ADH}$ secretion occur ${ }^{20,21}$ The cytokine storm that seems to occur in Covid-19 also stimulates the pulmonary vasoconstriction which also can induce $\mathrm{SIADH}^{22}$.

All these mechanisms discussed above could be associated with SIADH in a Covid-19 patient. Early detection and proper management can definitely at times be a lifesaving step in these group of patients.

\section{Conclusion:}

Hyponatraemia associated with SIADH in Covid-19 pneumonia is a newly emerging association/ complication of this viral infection. SIADH might be one of the causes for hyponatraemia in patients who are admitted in hospital for Covid-19 pneumonia. However it is necessary to diagnose the exact cause of hyponatraemia in order to properly treat these group of patients, reduce the duration of hospital stay and prevent mortality. More studies are needed to determine the association of Covid-19 with SIADH.

\section{References:}

1. Smith MD, McKenna K, Thompson CJ. Hyponatraemia. Clinical Endocrinology 2000;52:667-78.

2. Schrier RW, Bansal S. Diagnosis and management of hyponatremia in acute illness. Current Opinion in Critical Care. 2008;14:627-34

3. Guan WJ, Ni ZY, Hu Y, Liang WH, Ou CQ, He JX, et al. Clinical characteristics of coronavirus disease 2019 in China. http://dx.doi.org/10.1056/NEJMoa2002032

4. Huang C, Wang Y, Li X, Ren L, Zhao J, Hu Y, et al. Clinical features of patients infected with 2019 novel coronavirus in Wuhan, China. http://dx.doi.org/10.1016/S0140-6736(20)30183-5

5. Richard H Sterns. Causes of hypotonic hyponatremia in adults. https://www.uptodate.com/contents/causes-of-hypotonic-hyponatre mia-in-adults

6. GOH KP. Management of Hyponatremia. Am Fam Physician.15;69(10):2387-2394.

7. Hoorn EJ, Zietse R. Diagnosis and Treatment of Hyponatremia: Compilation of the Guidelines. J Am Soc Nephrol. 2017 May; 28(5): 1340-1349. doi: 10.1681/ASN.2016101139.

8. Ahmad K, Alrais ZF, Elkholy HM, et al. Effect of Early Correction of Hyponatremia on Neurological Outcome in Traumatic Brain Injury Patients. J Intensive \& Crit Care 2017, 3:1.

9. Joshua P Lang, Xiaowen Wang,Filipe A Moura, Hasan K Siddiqi, David A Morrow, Erin A Bohula · A current review of COVID-19 for the cardiovascular specialist, doi:10.1016/j.ahj.2020.04.025.
10. Yousaf Z, Al-Shokri SD, Al-soub H, and Mohamed MFH, COVID-19-associated SIADH: a clue in the times of pandemic. Am J Physiol Endocrinol Metab. 2020 Jun 1; 318(6) doi: 10.1152/ajpendo.00178.2020

11. Ravioli S, Niebuhr N, Ruchti C, Pluess E, Stoeckli T, Lindner G. The syndrome of inappropriate antidiuresis in COVID-19 pneumonia: report of two cases ,Clinical Kidney Journal,doi:10.1093/ckj/sfaa080

12. Sheikh MM, Ahmad E. COVID-19 Pneumonia: An Emerging Cause of Syndrome of Inappropriate Antidiuretic Hormone, doi: $10.7759 /$ cureus. 8841

13. Cuesta M, Slattery D, Goulden EL , Gupta S. Hyponatraemia in patients with community-acquired pneumonia; prevalence and aetiology, and natural history of SIAD. doi: 10.1111/cen.13937.

14. Papageorgiou AN, Moffatt M. Bilateral pneumonia and inappropriate secretion of antidiuretic hormone in a premature infant. Can Med Assoc J 114: 1119-1120, 1976

15. Share L. Acute reduction in extracellular fluid volume and the concentration of antidiuretic hormone in blood. Endocrinology 69: 925-933, 1961. doi:10.1210/endo-69-5-925

16. Anderson RJ, Harrington JT, Kassirer JP, Madias NE. Hospital-associated hyponatremia. Kidney Int 29: 1237-1247, 1986. doi:10.1038/ki.1986.134.

17. Share L, Levy MN. Cardiovascular receptors and blood titer of antidiuretic hormone. Am J Physiol 1962. 203: 425-428. doi:10.1152/ajplegacy.1962.203.3.425

18. Arndt JO, Gauer OH. Diuresis induced by water infusion into the carotid loop of unanaesthetized dogs. Pflugers Arch Gesamte Physiol Menschen Tiere 282: 301-312, 1965. doi:10.1007/BF00412505.

19. Jezova D, Skultetyova I, Tokarev D, Bakos P, Vigas M. Vasopressin and oxytocin in stress. Ann NY Acad Sci 771: 192-203, 1995. doi:10.1111/j.1749-6632.1995.tb44681.x.

20. Dunham-Snary KJ, Wu D, Sykes EA, Thakrar A, Parlow LRG, Mewburn JD, Parlow JL, Archer SL. Hypoxic pulmonary vasoconstriction: from molecular mechanisms to medicine. Chest 151: 181-192, 2017. doi:10.1016/j.chest.2016.09.001

21. Koizumi K, Yamashita H. Influence of atrial stretch receptors on hypothalamic neurosecretory neurones. J Physiol 285: 341-358, 1978. doi:10.1113/jphysiol.1978.sp012575.

22. Goodman RB, Pugin J, Lee JS, Matthay MA. Cytokine-mediated inflammation in acute lung injury. Cytokine Growth Factor.2003. Review 2003Dec;14(6): 523-535. doi:10.1016/s1359- 6101(03) 00059-5. 